\title{
The Implementation of Crisis Resolution Home Treatment Teams in Wales: Results of the National Survey 2007-2008
}

\author{
Richard Jones $^{1,2}$ and Sue Jordan ${ }^{*, 2}$ \\ ${ }^{1}$ Hywel Dda NHS Trust, Hafan Derwen, Parc Dewi Sant, Carmarthen, SA31 3BB, UK \\ ${ }^{2}$ School of Health Science, Swansea University, Swansea, SA2 8PP, UK
}

\begin{abstract}
Background: In mental health nursing, Crisis Resolution and Home Treatment (CRHT) services are key components of the shift from in-patient to community care. CRHT has been developed mainly in urban settings, and deployment in more rural areas has not been examined.
\end{abstract}

Aim: We aimed to evaluate CRHT services' progress towards policy targets.

Participants and Setting: All 18 CRHT teams in Wales were surveyed.

Methods: A service profile questionnaire was distributed to team leaders.

Findings: Fourteen of 18 teams responded in full. All but one were led by nurses, who formed the main professional group. All teams reported providing an alternative to hospital admission and assisting early discharge. With one exception, teams were 'gatekeeping' hospital beds. There was some divergence in clients seen, perceived impact of the service, operational hours, distances travelled, team structure, input of consultant psychiatrists and caseloads. We found some differences between the 8 urban teams and the 6 teams serving rural or mixed areas: rural teams travelled more, had fewer inpatient beds, and less medical input ( 0.067 compared to 0.688 whole time equivalents).. Most respondents felt that resource constraints were limiting further developments.

Implications: Teams met standards for CHRT services in Wales; however, these are less onerous than those in England, particularly in relation to operational hours and staffing complement. As services develop, it will be important to ensure that rural and mixed areas receive the same level of input as urban areas.

Keywords: Mental health nursing, crisis resolution, home treatment, rurality.

\section{INTRODUCTION}

Globally, health care systems are adapting to changes in the balance between acute and chronic conditions and the subsequent realignment of the equilibrium and equipoise between the burden of treatment relative to the burden of illness. This shift in the pattern of disease, from single episode and 'cure' to long-term management and 'care' has stimulated a reappraisal of the professional boundaries between doctors, with skills in acute medicine, to nurses with specialist areas of knowledge, caring skills and smaller case loads [1-3], particularly in community mental health nursing [4].

Crisis resolution and home treatment (CRHT) services have been in development for the past 25 years and rose to prominence in the UK in the 1990s, following the successful development of home treatment models globally [5]. The CRHT model has evolved gradually from earlier home treatment models, shaped by developments in the USA and Australia, which are now prominent in most Western countries [6].

*Address correspondence to this author at the School of Health Sciences, Swansea University, Singleton Park, Swansea SA2 8PP, UK; Tel: 01792 295789/518541; Fax: 01792 295487; E-mail: S.E.Jordan@swansea.ac.uk
CRHT services have been rapidly implemented in England and Wales with a 409\% increase in spending in real terms between 2002-3 and 2006-7. However, wide variation in the components of a CRHT service persist, attributed in part to regional variations in need [7].

\section{BACKGROUND}

Development of CHRT services is a response to the increasing evidence that mental health services may be better provided with early intervention within people's own homes and a recognition of the fact that this method of service delivery costs less than existing hospital based care. CRHT services aim to provide a realistic and safe alternative to hospital treatment for individuals of adult working age and beyond who are suffering from severe and enduring mental illness. This can be achieved by: assessment and treatment of mental health needs, including new prescribing, at home wherever possible; providing rapid response; gatekeeping hospital beds; working intensively with individuals for a short period of time and facilitating early discharge for individuals who have already been admitted to hospital.

There is international consensus on the advantages of providing crisis services. In the UK, these have formed a key part of mental health strategy, including the English National Service Framework for Mental Health and subsequent policy 
guidance $[8,9]$, and the Welsh priorities and planning guidance $[10,11]$. CRHT services can: reduce the number of hospital admissions; reduce the length of stay on inpatient units; increase cost effectiveness and provide more satisfactory care for service users and their families, with no significant difference in the rates of suicide or violence [5, 12-14].

Mental health policy and policy guidance in Wales prior to this survey $[10,11]$ had demanded the introduction of Crisis Resolution Home Treatment (CRHT) teams to serve the adult population. Despite this, there appeared to have been a varying degree of implementation of CRHT services across Wales.

CRHT services are relatively new and have largely been developed in urban areas [15]. Existing models of implementation are based upon urban models, and, as with all aspects of public health, further work is needed to explore their relevance to and feasibility in non-urban areas [16].

\section{THE STUDY}

Accordingly, we surveyed all CRHT teams in Wales to evaluate the service's progress towards the target set by WAG in 2004, (Service and Financial Framework target 17), that all health communities must put in place mental health CRHT services by 31st March 2006 [10]. The expected outcome was reduction in total mental health bed days for adults of working age by $5 \%$ in $2006-7$ and $25 \%$ in $2007-8$. This was compared against policy guidance issued a year later [11] (see Fig. 1).

\section{AIMS AND OBJECTIVES}

The purpose of this survey was to:

- $\quad$ audit and generate a baseline understanding of CRHT services in Wales between September 2007 and March 2008;

- $\quad$ explore how a largely urban model was being implemented in a small country with mixed pockets of rural population;
- examine whether services have met WAG (2004, 2005) $[10,11]$ targets (above), and where difficulties have arisen in achieving this;

- $\quad$ elicit what the teams felt their goals should be for the future.

\section{PARTICIPANTS AND SETTING}

Wales is a small country with a population of approximately 3 million people [17]. All CHRT teams in Wales were surveyed. This accounted for all major urban areas of Wales, but excluded some rural areas as they had not yet developed CRHT services in response to WAG policy.

\section{METHOD}

A service profile questionnaire, with a mixture of closed and open questions, was developed by the All Wales CRHT Network, involving the majority of CRHT services across Wales. This survey was discussed, developed and piloted with the network over several months. The network was also used to identify any other CRHT services in Wales. Any secondary mental health team that provided a service which could respond to individuals in crisis, within the guidance of WAG (2005) [11] policy, was invited to complete a service profile. These were distributed via email for return via email or post. Reminders were sent to those who had not responded within six weeks.

Teams were asked to describe whether they operated within an urban, rural or mixed area. There are no universally accepted criteria for rurality [16]. The criteria used for this survey were those adopted by the national survey of CRHT teams in England [15], which were adapted from Periman et al. (1984) [18]. An "urban" area was defined as a city or town with a population of at least 50,000; a rural area as one with no town of 10,000 or more and less than half the population living in towns/villages of 2500 or more; and mixed areas as meeting neither of the above criteria.

The Welsh guidance issued in 2005 recommended that $\mathrm{CRHT}$ services should, as a minimum:

- $\quad$ Be multidisciplinary with input either as a core part of the CRHT service or access to: medical; nursing; occupational therapy; psychology; support workers; approved social workers/social workers;

- Be multi-agency, i.e. health and social care services and others where appropriate, including non statutory sector providers;

- $\quad$ Be available to respond to psychiatric emergencies 24 hours a day 7 days a week 365 days a year;

- Provide a core service that is available as a minimum from 0900 to 2100 , with an on-call service available throughout the night;

- $\quad$ Provide intensive contact with service users and where appropriate carers for a short duration of up to six weeks;

- $\quad$ Act as a 'gatekeeper' to acute inpatient services, rapidly assessing individuals with acute mental health problems and referring them to the most appropriate service;

- Ensure that individuals experiencing acute and severe mental health difficulties are treated in the least restrictive environment and as close to home as clinically possible;

- Remain involved with the client until the crisis has resolved and the service user is linked into on-going care;

- $\quad$ Ensure where hospitalisation is necessary, active involvement in discharge planning;

- $\quad$ Be involved in care planning through the Care Programme Approach (CPA)

- $\quad$ Plan interventions that cover social, financial, housing as well as treatment needs;

- $\quad$ Provide support and education to carers/ family where appropriate. [11, p. 4]

Fig. (1). 
Staff were categorised by professional group and, for nurses, pay band. Establishment figures were measured as whole time equivalents (wtes) with 1.0 wte being equal to 37.5 hours per week. This was compared to recommendations made by the Sainsbury Centre for Mental Health [19], a UK charity that undertakes research, policy work and analysis to improve mental health practice and other public services.

This service evaluation was undertaken as an audit, and was approved as such by the NHS Trust Research and Development Department. Accordingly, the local Research Ethics Committee felt that ethical approval was not required.

\section{ANALYSIS}

Data were entered into into the statistical package for the social sciences (SPSS Inc., Chicago, Il., USA) for windows, version 16 and described [20].

Open questions were asked around some areas of practice where there appeared to be no clear established patterns in Wales, such as:

- $\quad$ "What arrangements does the Team have for medical cover, both day to day and in relation to responsibility for the Team caseload?"

- "How are you evaluating the work of the Team?

- Does the evaluation draw directly on the experience of users of the service and people that support them?"

- "What do you feel is particularly effective about the team?"

Responses to open questions were examined by content analysis to check the frequency and distribution of certain responses [21].

\section{RESULTS}

Of the 18 teams in Wales, 15 replied, response rate $84 \%$ and $14(78 \%)$ responded in full. No questionnaires were excluded as incomplete, although not all respondents were able to answer all questions.

\section{What the Teams are Able to do}

In terms of providing the core components of a CRHT service, all teams were able to provide an alternative to hospital admission for those experiencing acute mental health difficulties. All teams provided intensive contact with service users and, where appropriate, carers for up to six weeks. Fourteen teams $(93 \%)$ acted as "gatekeeper" to acute inpatient services, rapidly assessing individuals with acute mental health problems and referring them to the most appropriate service. All teams were involved in the early discharge of inpatients.

All teams accepted referrals for individuals experiencing psychosis, affective disorders and coexisting substance misuse disorders. There were variations around other presentations. Most teams would accept individuals experiencing anxiety disorders and personality disorders. Most would exclude social or relationship difficulties, a primary diagnosis of substance misuse, or organic disorders (Fig. 2).

All 15 teams had crisis beds available to them. Thirteen teams $(87 \%)$ had access to inpatient units for overnight admissions. One of these could also access a single bed within a local authority residential unit when a crisis bed was required as an alternative to using the traditional inpatient unit. The other two teams (13\%) shared access to a dedicated crisis house and a crisis recovery day unit, operating seven days a week, staffed by a multidisciplinary team. Only three

Diagnoses accepted by CRHT teams

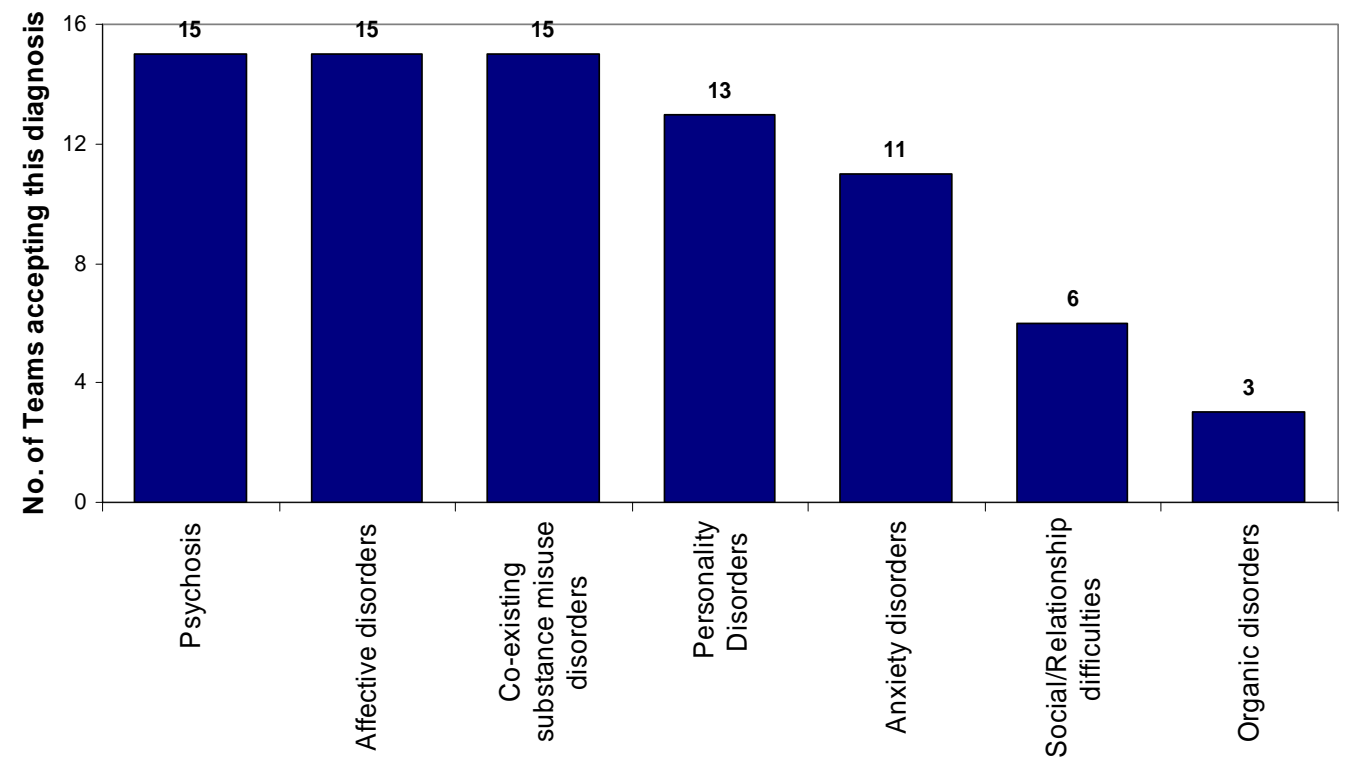

Fig. (2). Inclusion criteria for CRHT teams. 
other teams (20\%) had access to day hospital services. For any additional needs, other teams accessed existing community mental health teams, which are secondary mental health community services, typically operating within the hours of 9-5 Monday to Friday.

\section{Impact of the Teams}

Teams were asked how they assessed their impact and if their data indicated that they had been effective since their introduction. Eleven teams $(73 \%)$ routinely used patient satisfaction surveys, although it is not clear how these are distributed and collated. Eight teams (53\%) routinely gathered data to assess their team's impact on admissions, using: numbers of referrals; referral sources; assessments offered; numbers accepted by team; length of team intervention; numbers admitted; length of stay on ward; assessments for avoiding or for offering an alternative to admission and facilitating early discharge. Eight teams $(53 \%)$ reported that their data indicated that they had been effective in reducing admissions to acute psychiatric beds. Three teams $(20 \%)$ felt they were providing a rapid response to urgent referrals. Eight (53\%) stated that they had improved "whole systems working" that had improved the service users' experiences.

\section{"Urbanicity" of Teams}

Of the fifteen teams who responded, eight teams (53\%) operated in urban areas, six teams $(40 \%)$ in a mixed urbanicity area, and one team in a rural area. Only nine teams completed information on the approximate square mileage of their area. The smallest area reported was 40 square miles and the largest 987 square miles. Urban teams covered smaller areas (Fig. 3).

All urban teams travelled less than 26 miles to visit a service user. This could increase to 50 miles (Fig. 4a) for mixed or rural areas. The mean maximum travelling time to visit a single client was 52 minutes (SD 17), median 52.5.
With one exception, urban areas report less travelling time than $\mathrm{rural} /$ mixed areas (Fig. 4b).

Urban teams had an average of 29.8 inpatient beds available to them, mixed teams 22.8 beds and the one rural team had 16 beds. Urban teams appeared to have a greater number of beds accessible, however one urban team also had the lowest (11).

\section{Operational Hours of Teams}

Eight teams (53\%) operated a twelve hour service generally between $9 \mathrm{am}$ and $9 \mathrm{pm}$; there were variations to within 1 hour. Three teams $(20 \%)$ operate from $9 \mathrm{am}$ to midnight, and three $(20 \%)$ a 24 hour service. Ten $(67 \%)$ stated that their out of hours services were offered by other teams, most commonly the on-call psychiatrist. One stated that a telephone service was available from inpatient units (Fig. 5).

\section{Team Structure}

Fourteen teams $(93 \%)$ reported their establishment; the fifteenth was still in development. Two teams shared staff and it was unclear to what extent their roles and responsibilities were dedicated to CRHT work, therefore, they were removed from the calculations. Of the twelve teams considered, six $(50 \%)$ met the Sainsbury Centre for Mental Health guidance of minimum team of 10-11 wte in urban areas [19], four met Department of Health [9] recommended team of 14 wte clinical staff, excluding psychiatrists. The three oldest established teams in the country had not developed to meet Sainsbury minimum recommended guidelines. They also lacked full multidisciplinary establishment (Table 1).

The mean number of whole time equivalents per team was 11 (SD 4), median 9.5, range 5.6-17.4. This was related to the size of population served by the team but not the time and distance travelled. This establishment figure excludes psychiatrists and administration staff in order to provide a

Square mileage of the areas covered

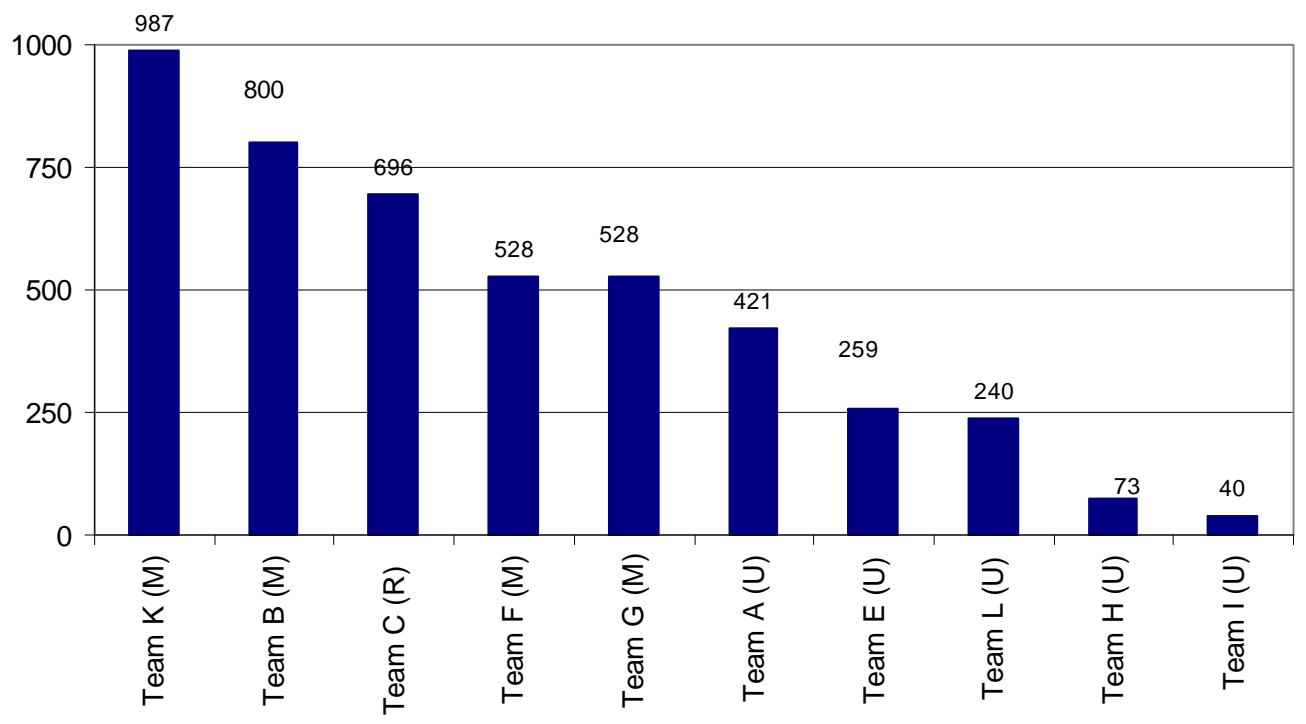

Fig. (3). The measure of urbanicity is indicated by urban (U), mixed (M) and rural (R). 


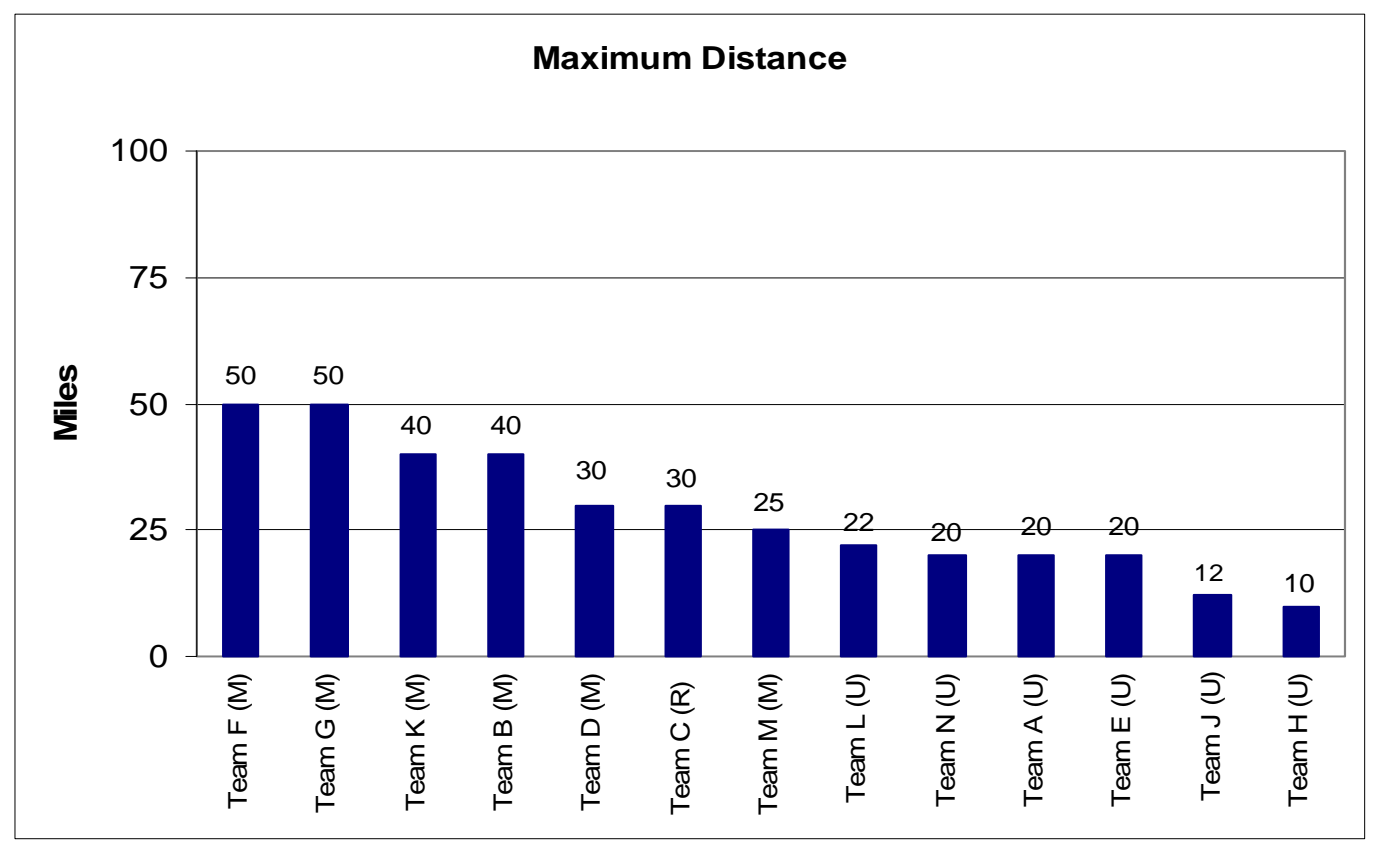

Fig. (4a). Maximum distances travelled by teams.

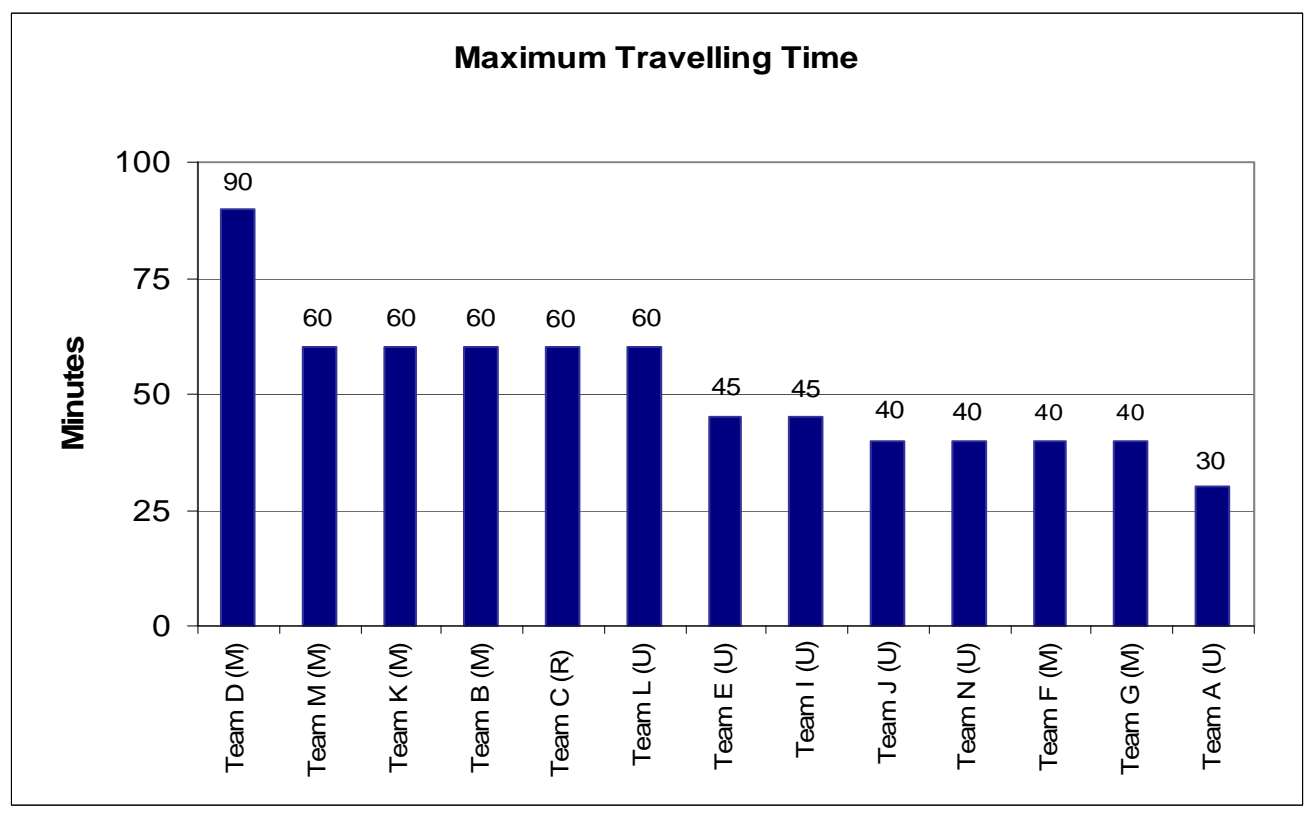

Fig. (4b). Teams' minimum travelling times.

figure for the clinical team for comparison with Sainsbury guidance [19].

\section{Multidisciplinary Input}

Most CRHT team members were registered nurses (49.8\%, 73.3 wte), followed by nursing assistants $(31.1 \%, 46$ wte) (Fig. 6). Nurses and nursing assistants therefore accounted for $80.9 \% \quad(119.3$ wte $)$ of teams' total establishment. Social workers accounted for 5.1\% (7.6wte) of teams overall and occupational therapists accounted for $2.3 \%$ (3.4wte). Seven teams $(47 \%)$ reported no social worker and eight teams (53\%) reported having no occupational therapist. There were no differences between urban and other teams. Three teams $(20 \%)$ had only nursing professionals.

\section{The Input and Role of Psychiatrists}

One team had a dedicated full time consultant psychiatrist; another had 0.5 wte dedicated consultant psychiatrist. Only urban teams had any dedicated consultant psychiatrist input, and they were more likely to have a multi disciplinary establishment. Four of eight urban teams had medical input, compared to one of $6 \mathrm{mixed} /$ rural teams: urban teams have a mean of 0.688 medical wtes, and mixed/rural teams 0.067 . Six teams $(40 \%)$ have access to some dedicated medical input between 9-5 Monday to 
Hours of operation

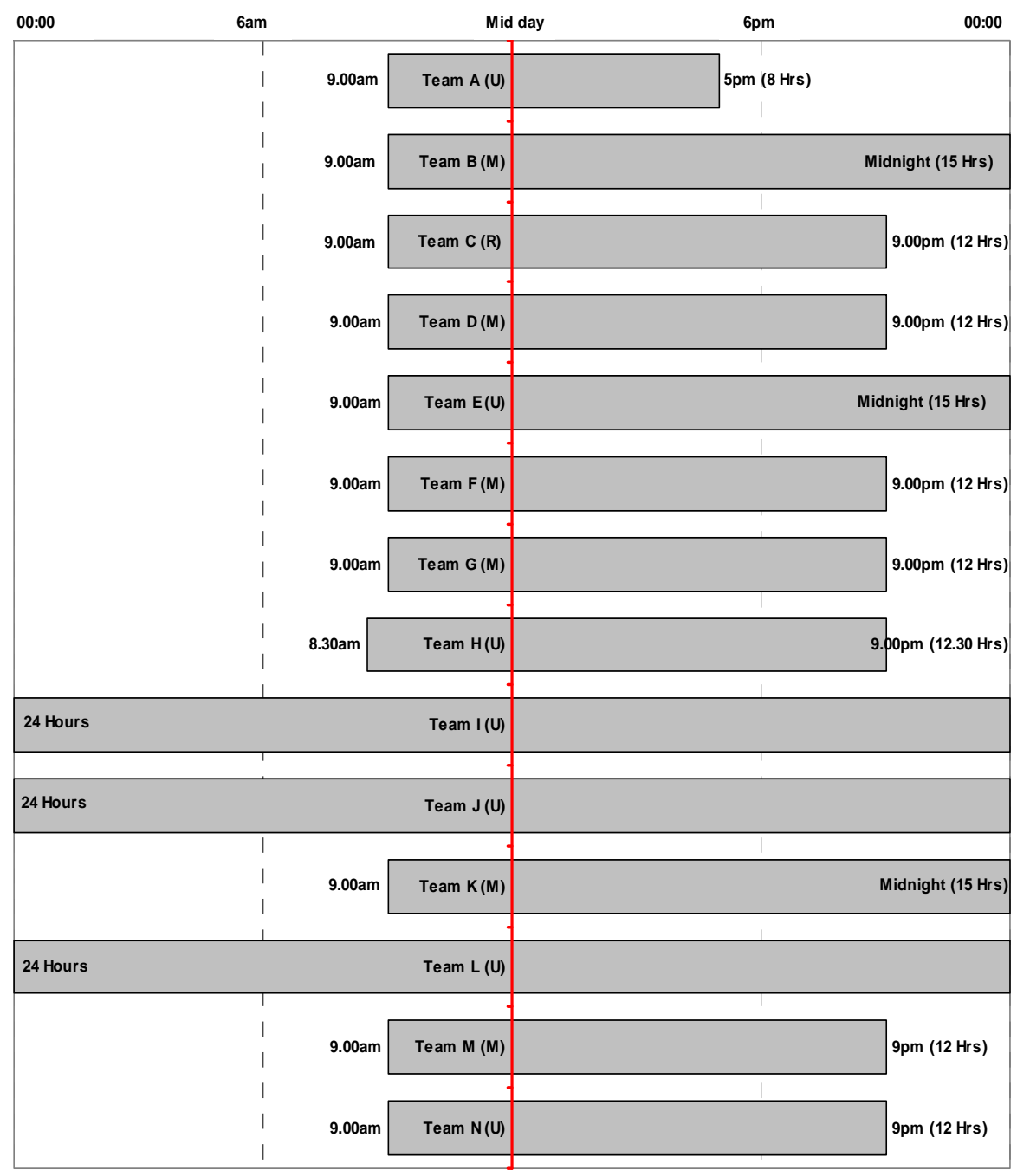

Fig. (5). Hours of operation.

Friday. All other teams were able to draw on external medical expertise, such as community mental health teams or inpatient units. Welsh government policy [11] dictates that teams should have access to a multi disciplinary team as a minimum, and it appears that all teams comply with this.

\section{Caseloads}

The mean maximum caseload was 16.8 clients (SD 5.3), median 15.5 , range $7-27$. The maximum caseload for any team was 27. This was the maximum caseload size allowed at any time, and occurred in an urban area. The smallest caseload was 7 in a mixed area. Urban teams had a mean maximum caseload of 18. Mixed teams had a mean maximum caseload of 14 . The one rural team identified a maximum caseload of 20 (Table 2). The three teams in development could not be considered.

\section{Future Developments}

Teams were asked to identify their goals for the next twelve months. All teams stated that they intended to develop further, consolidate their practice and develop new ways of working. Four teams $(27 \%)$ identified that they needed to improve their early discharge role, and another four teams (27\%) that they intended to employ more staff.

Teams were asked to identify the obstacles to further development towards full implementation of the Policy Implementation Guidance document [11]. Thirteen teams $(87 \%)$ cited human and financial resources as the main obstacle to development. Two teams (13\%) described problems with releasing staff from other areas within the local health community or using non-permanent staff. Three teams $(20 \%)$ had no multidisciplinary (social workers, 
Table 1. Description of Staff Employed

\begin{tabular}{|c|c|c|c|c|c|c|c|c|c|c|c|c|}
\hline \multicolumn{13}{|c|}{ Establishment of Teams } \\
\hline$\underline{\underline{x}}$ & 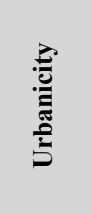 & 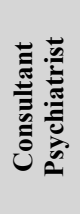 & 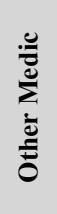 & 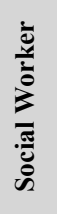 & 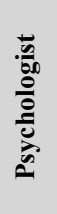 & 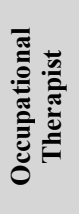 & 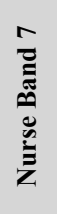 & 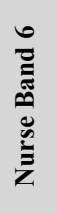 & 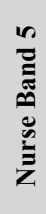 & 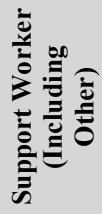 & 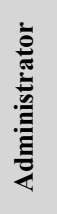 & 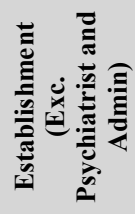 \\
\hline Team A & Urban & & & 0.6 & & & 1 & 2 & 1 & 1 & & 5.6 \\
\hline Team B & Mixed & & 0.4 & & & 0.4 & 0.8 & 4 & & 2 & & 7.2 \\
\hline Team C & Rural & & & & & & 1 & 2.5 & & 5 & & 8.5 \\
\hline Team D & Mixed & & & 1 & & & & 3 & & 5 & 1 & 9 \\
\hline Team E & Urban & & & & & & 1 & 3 & & 3 & & 7 \\
\hline Team F* & Mixed & & & 3.5 & & 1.6 & 2 & 2 & 5 & & & 14.1 \\
\hline Team G* & Mixed & & & 0.5 & & 1.6 & 2 & 2 & 5 & & & 11.1 \\
\hline Team $\mathrm{H}$ & Urban & & & 1 & & 1 & 1 & 5 & & 2 & & 10 \\
\hline Team I & Urban & 1 & 1 & 2 & 0.4 & 1 & 1 & 8 & & 5 & & 17.4 \\
\hline Team J & Urban & 0.5 & & & 0.5 & & 1 & 8 & & 6 & 1 & 15.5 \\
\hline Team K & Mixed & & & & & & 1 & 5 & & 3 & & 9 \\
\hline Team L & Urban & & 2 & 2 & 0.6 & & 1 & 10 & & 5 & 2 & 18.6 \\
\hline Team M & Urban & & 1 & & & 1 & 1 & 6 & & 7 & & 15 \\
\hline Team N & Urban & & & 1 & & & 1 & 5 & & 5 & 1.5 & 12 \\
\hline
\end{tabular}

* Report that they 'share' 11.1 team members. Figures expressed as whole time equivalent.

occupational therapists, psychologists) staff. One team experienced problems funding 24 hour services, and two (13\%) with gatekeeping.

\section{DISCUSSION}

This survey reports a baseline review of CRHT services in Wales as they existed in 2007/2008 from the perspective

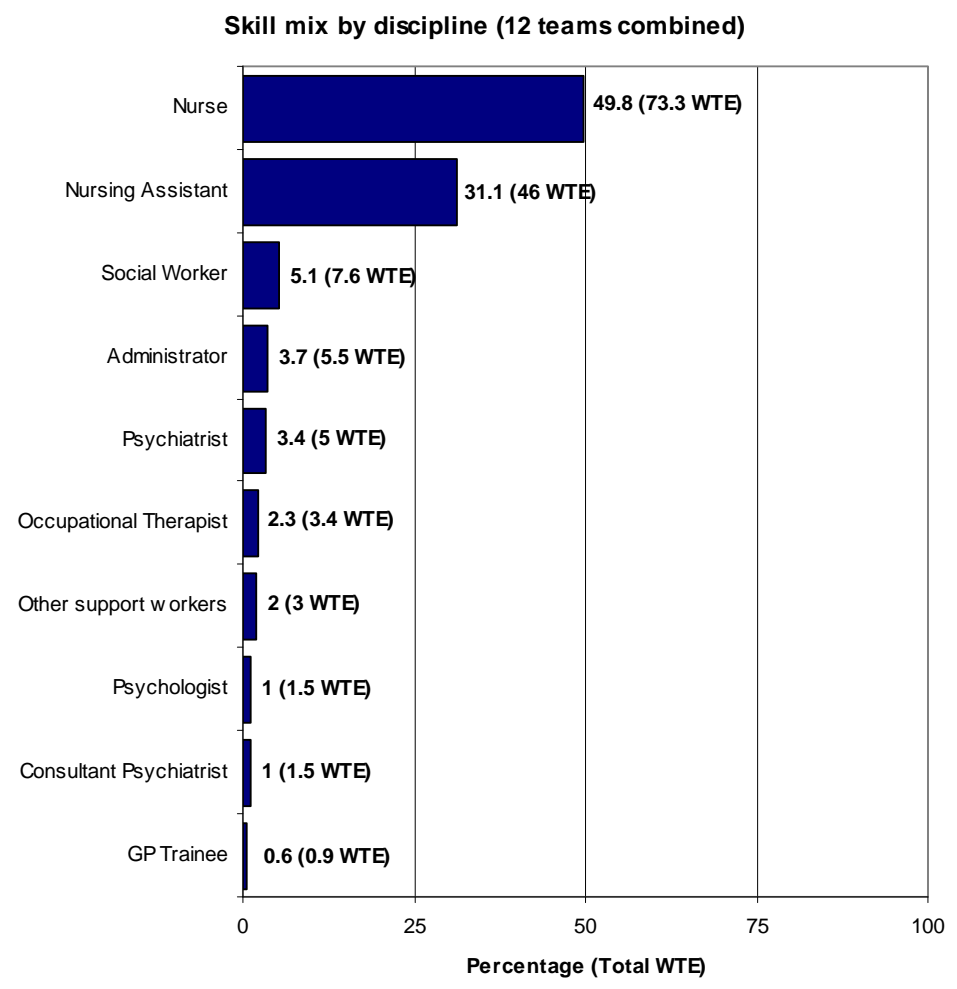

Fig. (6). Skill mix by discipline. 
of the CRHT managers and team leaders, and how these have been developed compared to national targets and guidance issued by the Welsh Assembly Government.

The WAG position prior to March 2009 was that "organisations must have developed Crisis Resolution Home Treatment services that provide a single point of contact to high quality services and meaningful advice directly from clinical staff" [22]. There were no robust systems in place for performance management, nor was policy prescriptive in what should constitute a CRHT service.

There were disparities in the CRHT services across Wales, and variations in team sizes and multidisciplinary input. Due to the diverse geography and demography of Wales teams may need to adapt to meet differing service needs. There were large variations in the areas covered by teams, their travelling times and distances. Overall, a trend has appeared for services operating within the hours of 9am to $9 \mathrm{pm}$, which is congruent with WAG but not UK policy directives and guidelines.

Since the presentation of a report based on this survey [23] the Welsh Assembly Government [22, 24] introduced a system of performance management to ensure that CRHT services achieve their intended targets. These have been standardised as:

- $\quad$ providing a rapid response to urgent referrals (face to face assessment within four hours),

- $\quad$ gatekeeping $95 \%$ of all admissions to hospital between the hours of 09.00 to 21.00 ,

- $\quad$ providing a review within 24 hours of admission for $100 \%$ of admissions who had not been gatekept by the CRHT prior to admission,

- $\quad$ focussing on the target population (individuals with a severe mental illness, experiencing a crisis due to their mental illness).

- $\quad$ involvement with the individuals for up to six weeks.

Table 2. Team Caseloads and Staffing

\begin{tabular}{|c|c|c|}
\hline Team & Maximum Caseload & Total WTE Per Team \\
\hline \hline Team A (U) & 12 & 5.6 \\
\hline Team B (M) & 14 & 7.2 \\
\hline Team C (R) & 20 & 8.5 \\
\hline Team D (M) & 7 & 9 \\
\hline Team E (U) & 14 & 7 \\
\hline Team H (U) & 16 & 10 \\
\hline Team I (U) & 22 & 17.4 \\
\hline Team J (U) & 15 & 15.5 \\
\hline Team K (M) & 20 & 9 \\
\hline Team L (U) & 27 & 16.6 \\
\hline Team M (U) & 20 & 15 \\
\hline Team N (U) & 15 & 12 \\
\hline
\end{tabular}

\section{STUDY LIMITATIONS}

This survey encompassed all the CHRT services in one small European country. While some findings are similar to those reported in England, UK [15], their saliency to nursing services in other countries must be based on inference and practical adequacy. As with all cross sectional data, association does not imply causation, and the small sample size necessitates cautious interpretation of findings.

This survey has focused on distinct CRHT services; however there were three teams $(20 \%)$ identified as being in development, with CRHT services being offered from existing CMHT teams. In consideration of the respondent burden, we were unable to gain full information on a number of issues, such as training needs, and interventions administered, and it is hoped that we shall be able to address this in future work.

\section{A SERVICE IN DEVELOPMENT}

At the time of data collection, CRHT services were not available in all parts of Wales. The WAG requirement to provide CRHT services throughout Wales had not been met. Additionally, whilst fifteen teams responded to the survey, three $(20 \%)$ considered that were still developing a toward a CRHT service, and there have been further changes.

CRHT services in Wales have been in development since 2002. They appear to hold mixed views on their effectiveness to date, and the majority, thirteen teams (87\%), indicated that lack of resources prevented them from achieving this. Most teams $(13,87 \%)$ stated that human and financial resources were the biggest obstacle to providing a robust service and this is supported by the evidence gathered on team establishments with limited involvement from psychiatrists, psychologists, social workers and occupational therapists. This is consistent with the results of the English survey [15]. There appears to have been a focus on developing CRHT services in urban areas since 2005 and there are now more CRHT services in urban areas than elsewhere, which is consistent with the picture in England provided by Onyett et al. [15].

While the government in Wales has demanded the provision of services between 09.00 and 21.00, English policy guidance [9] demands 24 hours services, which is consistent with recommendations made within the literature evidencing the use of CRHT services [5, 7, 19, 25].

The UK National Audit Office [7] notes that fully multidisciplinary teams, including dedicated input from consultant psychiatrists, are able to provide better quality of care and integration within mental health services. Despite this, teams in Wales have been developed primarily using the nursing profession. Nurses and nursing assistants account for $80.9 \%$ (119.3wte) of the total establishment measured. Consultant psychiatrists were significantly absent from teams. Only one team had a dedicated full time consultant, and another had a dedicated consultant psychiatrist $0.5 \mathrm{wte}$. Seven teams $(47 \%)$ had no social worker and eight $(53 \%)$ no occupational therapist. Urban teams are more likely to have a multidisciplinary team; however all teams indicated that they could draw on multidisciplinary support from existing community services. 
Table 3. Comparisons of Some of the Key Features of a CRHT Service

\begin{tabular}{|c|c|c|c|c|}
\hline & $\begin{array}{l}\text { Department of } \\
\text { Health Policy } \\
\text { Guidance [9] }\end{array}$ & $\begin{array}{l}\text { Sainsbury Centre for } \\
\text { Mental Health [19] }\end{array}$ & $\begin{array}{l}\text { Welsh Assembly Government } \\
\text { Policy Guidance [11] }\end{array}$ & $\begin{array}{c}\text { Welsh Assembly Government Annual } \\
\text { Operating Framework }[22,24]\end{array}$ \\
\hline $\begin{array}{l}\text { Gatekeep hospital } \\
\text { beds }\end{array}$ & Yes & $\begin{array}{l}\text { Yes: most or all } \\
\text { admissions. }\end{array}$ & Yes & Yes. $95 \%$ of admissions. \\
\hline $\begin{array}{l}\text { Be multidisciplinary } \\
\text { input as a core of the } \\
\text { service, including a } \\
\text { senior psychiatrist. }\end{array}$ & Yes & Yes & $\begin{array}{l}\text { Yes, or have access to } \\
\text { multidisciplinary staff. }\end{array}$ & $\begin{array}{c}\text { Yes, or have access to multidisciplinary } \\
\text { staff. }\end{array}$ \\
\hline 24 hours services & Yes & Yes & $\begin{array}{l}09.00-21.00 \text { with an on-call } \\
\text { system outside these hours. }\end{array}$ & $\begin{array}{l}09.00-21.00 \text { with an on-call system } \\
\text { outside these hours. }\end{array}$ \\
\hline $\begin{array}{l}\text { Rapid response to } \\
\text { referrals }\end{array}$ & $\begin{array}{l}\text { Yes. Within one } \\
\text { hour. }\end{array}$ & Yes & $\begin{array}{l}\text { Yes. No target but refers to } \\
\text { England being one hour. }\end{array}$ & $\begin{array}{l}\text { Yes. For urgent referrals: provide a face } \\
\text { to face assessment within } 4 \text { hours. }\end{array}$ \\
\hline Suggested team size & $\begin{array}{l}14 \text { (excluding } \\
\text { medical staff) for a } \\
\text { population of } \\
150,000 .\end{array}$ & $\begin{array}{l}14 \text { (excluding medical } \\
\text { staff) for a population } \\
\text { of } 150,000 . \text { Minimum } \\
\text { of } 10-11 \text { staff. }\end{array}$ & Not mentioned. & Not mentioned. \\
\hline $\begin{array}{l}\text { Focus on target } \\
\text { population. }\end{array}$ & Yes. & Yes. & Yes. & Yes. \\
\hline $\begin{array}{l}\text { Time limited } \\
\text { intervention }\end{array}$ & $\begin{array}{l}\text { Yes but time limit } \\
\text { not specified. Also } \\
\text { notes that teams } \\
\text { should remain } \\
\text { involved until the } \\
\text { crisis is resolved. }\end{array}$ & $\begin{array}{l}\text { Teams should remain } \\
\text { involved until crisis is } \\
\text { resolved. }\end{array}$ & $\begin{array}{l}\text { Up to six weeks. Also notes that } \\
\text { teams should remain involved } \\
\text { until the crisis is resolved. }\end{array}$ & $\begin{array}{l}\text { Up to six weeks. Also notes that teams } \\
\text { should remain involved until the crisis is } \\
\text { resolved. }\end{array}$ \\
\hline $\begin{array}{l}\text { Facilitating early } \\
\text { discharge }\end{array}$ & Yes & Yes & Yes & Yes. \\
\hline
\end{tabular}

Guidance issued by the Department of Health [9] and Sainsbury Centre for Mental Health [19] suggests team sizes of 10-14 people for a population of 150,000 . Of the teams surveyed only six $(40 \%)$ were able to meet the minimum figure. These were in urban areas. CRHT services which cover more rural areas must also take into account the potentially long distances and travelling times within their establishment figures. There is currently no universally recognised method of accounting for the establishment needs of rural CRHT services, which suggests that further research is required, and geographical variation should be taken into consideration in future planning [26].

Most teams felt that they were able to provide the core elements of a CRHT service. All were able to provide an alternative to hospital admission, intensive home treatment for a period of up to six weeks and facilitate early discharge. Fourteen teams (93\%) stated that they were able to gate keep hospital beds. The involvement of CRHT teams in Mental Health Act assessments is currently low with only three teams $(20 \%)$ indicating that they are included as an integral part of the process. If CRHT teams are to act as a gatekeeper for inpatient services then this figure should be higher.

Alternatives to hospital admission are limited in Wales. Only two teams had access to a dedicated crisis house and one team had access to a crisis bed in a local authority funded residential unit. Teams have otherwise made use of existing service provision to provide alternative resources. This appears to support the view of the National Audit Office [7], that whilst alternatives to admission as well as home treatment can provide valuable support, their provision is inconsistent.

\section{MEDICALLY UNDERSERVED LOCATIONS}

Teams were staffed primarily by nurses. Growth in demand for medical care has outstripped the available supply of doctors in many areas of the UK [27] particularly economically deprived communities and unpopular specialities. Accordingly, nurses' roles are expanding to include delivery of complete episodes of care as envisaged in the NHS Plan 2000 [28]. Our study indicated that management of acute episodes of mental illness and gate keeping of acute beds has devolved to nurses: whether this may be viewed as recognition of burgeoning demand, costcontainment or a challenge to the hegemony of medicine is uncertain $[29,30]$.

Consultant psychiatrists, social workers and occupational therapists were largely absent from teams; however these professions were accessed from existing CMHT resources. Consequent difficulties in providing a multidisciplinary service require further exploration. Non-urban teams had no dedicated psychiatrists and fewer medical staff $(0.067$ wtes, compared to 0.688 wtes). This reflects the reduced accessibility of primary care and services associated with rurality in the UK [31], international reviews [32], and the USA [33]. Some problems, such as suicide in adults [34, 35], depression and anxiety [36], substance misuse [37], may be more prevalent in rural areas. Given the socio-economic profile of many clients of mental health services, and findings that rurality accentuates the effects of socioeconomic disadvantage [32], this inequality of access to medical input is cause for concern. 


\section{Box 1. Recommendations for Practice}

Responses to this survey and wider reading indicated that in order for
CRHT teams to focus on their core functions they should:
- be developed with due consideration to local geography and
travelling times;
- have multi disciplinary input as a core of the team to address the
health needs, social needs and occupational functioning of clients;
- operate a minimum service of $9 \mathrm{am}$ to $9 \mathrm{pm}$. Developing 24 hours
services may be dependent on local need to provide a cost effective
service;
- have access to other services such as crisis beds to assist in managing
crisis;
- have a consistent method of gathering data on performance
management;
- receive the resources required to enable them to meet the minimum
policy guidance provided by the Welsh Assembly Government.

\section{Box 2. Recommendations for Research}

Further review and audit to determine how services are being delivered should:

- have sufficient resources available to ensure consistent completion of service profiles;

- have a current data on key performance indicators for CRHT services [in Wales];

- seek to clarify a definition of early discharge and ensure that this is measurable in terms of performance management;

- identify the current range of interventions employed by CRHT practitioners;

- identify the training needs of these teams;

- centralise data collection and audit to allow consistency and relieve clinicians of an administrative burden.

In medically underserved locations and unpopular specialities, clinical care is hampered by the 'Inverse Care Law' [38] (the more the clinical need, the fewer the doctors), and the 'Inverse Interest Law' [39] (the commoner the condition, the less the medical interest). Whether development of crisis teams staffed by nurses, practising autonomously, will erode or accentuate these inequalities in service delivery between urban and rural, rich and poor will need further investigation.

To date, there appears to have been limited success in applying a largely urban model of CRHT services to a small country with mixed pockets of population. Lack of resources was cited as the single biggest obstacle to achieving this, and non-urban teams were less well resourced. While the number of staff employed in each team reflected the population size, it did not take account of the increased travelling needed outside urban areas. While distance to hospital is crucial in some areas of medicine [40], further research is needed to explore the impact on acute mental health episodes.

Policy in England and Wales has, perhaps unsurprisingly, developed similarly; however there are some variations which reflect the differences between the two countries. Most notably, Welsh policy has not directed health care providers on the minimum establishment of the team in terms of core multidisciplinary input, team size, or hours of operation. Table 3 compares key elements drawn from the policies and compared with guidance issued by the Sainsbury Centre for Mental Health:

\section{CONCLUSION}

This work has highlighted the need for practice developments (Box 1) and further research (Box 2) in relation to local geography. Worldwide, there is growing recognition that the key to improving health care for all citizens requires the expansion of nursing roles. In developing countries and the less affluent and more remote areas of developed countries, this necessitates nurses assuming new responsibilities, formerly the preserve of the medical profession.

\section{ACKNOWLEDGEMENTS}

This paper was presented at the All Wales CRHT Conference on $25^{\text {th }}$ September 2008 and is based on a report to the All Wales Crisis Resolution Home Treatment Network.

We should like to thank the All Wales Crisis Resolution Home Treatment Network, and in particular Brahms Robinson of the Newport Home Treatment Team, for the work undertaken in developing the service profiles, identifying teams and assistance in gathering data for this survey. Mr. Emrys Elias, Senior Performance Improvement Manager (Mental Health), NHS Delivery and Support Unit, Wales, for his assistance in clarifying Welsh government policy. We should also like to thank Amorelle Jones and the Clinical Effectiveness and Audit Department within the mental health directorate of Hywel Dda Health Board for their assistance in collating the data.

\section{ABBREVIATIONS}

CMHT $=$ Community Mental Health Team

CRHT $=$ Crisis Resolution Home Treatment

NHS $=$ National Health Service

WAG $=$ Welsh Assembly Government

Wte $=$ Whole time equivalent

\section{REFERENCES}

[1] Bodenheimer T. Disease management - problems and pitfalls. N Engl J Med 1999; 340(15): 1202-5.

[2] DoH (Department of Health). A health Service of all the talents: Developing the NHS workforce. London: HMSO 2000.

[3] NHS (National Health Service). The NHS Plan: a plan for investment; a plan for reform. Norwich: HMSO 2000.

[4] Jordan S. Managing adverse drug reactions: an orphan task. Developing nurse-administered evaluation checklists. J Adv Nurs 2002; 38(5): 437-48.

[5] Smyth MG, Hoult J. The home treatment enigma. Br Med J 2000; 320: 305-9.

[6] Johnson S, Thornicroft G. The development of crisis resolution and home treatment teams. In: Johnson S, Needle J, Bindman J, Thornicroft G, Eds. Crisis resolution and home treatment in mental health. Cambridge: Cambridge University Press 2008.

[7] NAO (National Audit Office). Helping people through mental health crisis: the role of crisis resolution and home treatment services. London 2007.

[8] DoH (Department of Health). National service framework for mental health: modern standards and service models. London 1999. 
[9] DoH (Department of Health). The mental health policy implementation guide: crisis resolution/home treatment teams. London 2001.

[10] WAG (Welsh Assembly Government). Annual priorities and planning guidance for the service and financial framework 20052006. WHC (2004) 083. Cardiff 2004.

[11] WAG (Welsh Assembly Government). Policy implementation guidance on the development of crisis resolution/home treatment (cr/ht) services in Wales. Cardiff 2005.

[12] Joy CB, Adams CE, Rice K. Crisis intervention for people with severe mental illnesses: the cochrane database of systematic reviews. 4. New York: John Wiley \& Sons Ltd 2004.

[13] Johnson S, Nolan F, Pilling S, et al. Randomised controlled trial of acute mental health care by a crisis resolution team: the north Islington crisis study. Br Med J 2005; 331: 599-602.

[14] Glover G, Arts G, Babu KS. Crisis resolution/home treatment teams and psychiatric admission rates in England. Br J Psychiatry 2006; 189: 441-5.

[15] Onyett S, Linde K, Glover G, Floyd S, Bradley S, Middleton H. Implementation of crisis resolution/home treatment teams in England: national survey 2005-2006. Psychiatric Bull 2008; 32: 374-7.

[16] Farmer JC, Baird AG, Iversen L. Rural deprivation: reflecting reality. Br J Gen Pract 2001; 51(467): 486-91.

[17] ONS (Office for National Statistics). Wales: Regional Profile. Office for National Statistics. 2009; Available from: http://www. statistics.gov.uk [Cited: 13 August 2009];

[18] Periman B, Hartman EA, Bosak J. A study of mental health administrators and systems utilising a four-part urban/rural taxonomy. Commun Ment Health J 1984; 20(3): 202-11.

[19] McGlynn P, Ed. In: crisis resolution and home treatment: a practical guide. London: The Sainsbury Centre for Mental Health 2006.

[20] Field A. Discovering statistics using spss. $3^{\text {rd }}$ ed. London: SAGE 2009.

[21] Silverman D. Interpreting qualitative data. London: SAGE 2001

[22] WAG (Welsh Assembly Government). NHS Wales: annual operating framework 2009/10. Cardiff 2009.

[23] Jones R, Robinson B. A national survey of crisis resolution home treatment teams in Wales. 2008; Available from: http://www.wales. nhs.uk/sites3/docopen.cfm?orgId=776\&id=104294 [Cited: 24 August 2009].

[24] WIGSB (Welsh Information Governance and Standards Board). DSC Notice: DSCN (2009) 07 (W). Cardiff 2009.
[25] SCMH (Sainsbury Centre for Mental Health). mental health topics: crisis resolution. London 2001.

[26] Turnbull J, Martin D, Lattimer V, Pope C, Culliford D. Does distance matter? Geographical variation in GP out-of-hours service use: an observational study. Br J Gen Pract 2008; 58(552): 471-7.

[27] Medical Workforce Standing Advisory Committee. Planning the medical workforce. third report. London: Department of Health, the Stationery Office 1997.

[28] NHS (National Health Service). The NHS plan, a plan for investment; a plan for reform. Norwich: HMSO; 2000.

[29] Jordan S, Hughes D. Continuing professional education and the everyday realities of practice. In: Allen D, Hughes D, Jordan S, Prowse M, Snelgrove S, Eds. Nursing and the division of labour. Health care. Basingstoke: Palgrave 2002.

[30] Jordan S, Griffiths H. Nurse prescribing: developing the evaluation agenda. Nurs Stand 2004; 18 (29): 40-4.

[31] Watt IS, Franks AJ, Sheldon TAJ. Health and health care of rural populations in the UK: is it better or worse? Epidemiol Commun Health 1994; 48(1): 16-21.

[32] Smith KB, Humphreys JS, Wilson MG. Addressing the health disadvantage of rural populations: how does epidemiological evidence inform rural health policies and research? Aust $\mathrm{J}$ Rural Health 2008; 16(2): 56-66.

[33] Laditka JN, Laditka SB, Probst JC. Health care access in rural areas: evidence that hospitalization for ambulatory care-sensitive conditions in the United States may increase with the level of rurality. Health Place 2009; 15(3): 731-40.

[34] Eberhardt MS, Pamuk ER. The importance of place of residence: examining health in rural and nonrural areas. Am J Public Health 2004; 94(10):1682-6.

[35] Middleton N, Sterne JA, Gunnell DJ. An atlas of suicide mortality: England and Wales, 1988-1994. Health Place 2008; 14(3):492-506.

[36] Walters K, Breeze E, Wilkinson P, Price GM, Bulpitt CJ, Fletcher A. Local area deprivation and urban-rural differences in anxiety and depression among people older than 75 years in Britain. Am J Public Health 2004; 94(10):1768-74.

[37] Lambert D, Gale JA, Hartley D. Substance abuse by youth and young adults in rural America. J Rural Health 2008; 24(3): 221-8.

[38] Hart JT. The inverse care law. Lancet 1971; 7696: 405-12.

[39] Lewis G, Wessely S. 'The epidemiology of fatigue: more questions than answers', J Epidemiol Commun Health 1992; 46, 2: 92-7.

[40] Wei L, Lang CC, Sullivan FM, et al. Impact on mortality following first acute myocardial infarction of distance between home and hospital: cohort study. Heart 2008; 94(9):1141-6. 